\title{
How can we improve the quality of reporting family history in colorectal cancer care? (And why does it matter?)
}

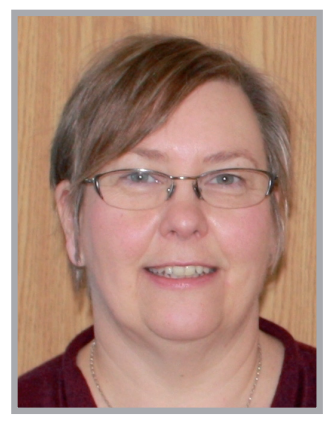

Brenda J Wilson*

\author{
"The overall consequences of widely adopting \\ family history in risk assessment are influenced \\ by the underlying prevalence of colorectal \\ cancer, and the effectiveness of existing policies \\ on prevention, screening and treatment."
}

\section{Family history \& colorectal cancer}

Family history $(\mathrm{FH})$ represents the integration of shared genomic and environmental risk factors [1]. First-degree relatives share half of their genomic information, as well as ways and places of living and working. Even if the molecular etiology of a condition is not fully understood, FH offers insight into disease susceptibility, and may provide a rational basis for personalizing preventive and healthcare interventions [2]. FH is, of course, the primary marker of genetic syndromes such as familial adenomatous polyposis and Lynch syndrome (hereditary nonpolyposis colorectal cancer [CRC]), but these account for no more than $6 \%$ of all CRC cases [3]. To this familial clustering should be added thought to be due to (as yet unidentified) genetic variants, which may account for a further $15-25 \%[4,5]$.

Setting aside known genetic syndromes, however, there is clear evidence that having just one affected first-degree relative raises a person's lifetime risk of CRC by a factor of approximately two, further increased with additional affected relatives and earlier age of diagnosis $[6,7]$. There is also evidence of longer survival in colon (but not rectal) cancer patients with a positive $\mathrm{FH}$ [8-12], although this has not been confirmed in all studies [13-15]. It has also been observed that CRC patients with a positive $\mathrm{FH}$ may have a higher incidence of secondary cancers $[8,12,16]$. These findings are thought-provoking, but require further investigation.

\section{Should $\mathrm{FH}$ be used routinely in CRC care? \\ The main area for considering FH in CRC care is in risk assessment and surveillance. Some argue that taking a FH is 'low-tech', noninvasive and within the skillset of every health professional, therefore it is an easy approach to personalizing disease risk assessment [17]. However, others argue that its use requires further evidence [18], even if it does not appear, on face value, to cause harm [19]. Enquiring about FH is time consuming and has resource implica- tions if systematically applied in primary}

"...there is clear evidence that having just one affected first-degree relative raises a person's lifetime risk of colorectal cancer..." 


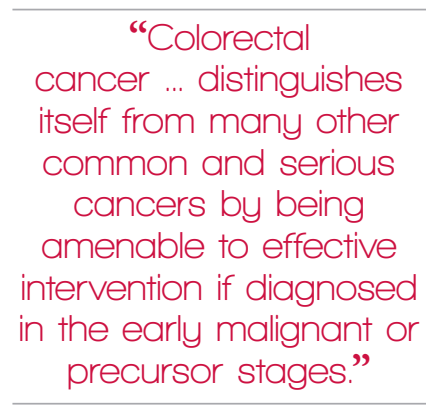

"Colorectal

cancer ... distinguishes

itself from many other

common and serious

cancers by being

amenable to effective

intervention if diagnosed

precursor stages." and general healthcare settings [20]. Although $\mathrm{CRC}$ is a relatively frequent cancer, the increase in risk with $\mathrm{FH}$ is only poorly predictive of disease development in the individual patient [19]. What are the arguments, therefore, for building FH into CRC risk assessment and clinical management?

For the most compelling rationale, we need to take a population perspective. Worldwide, CRC accounts for approximately 700,000 new cases, and approximately 600,000 deaths, per year [101]. In countries with well-developed healthcare systems, overall 5-year survival is approximately $50 \%$. Prognosis is strongly associated with stage at diagnosis: in the UK, 5-year survival exceeds $90 \%$ for those diagnosed at Dukes' stage A, falling to approximately 75,50 and $6 \%$ for stages B, $\mathrm{C}$ and $\mathrm{D}$, respectively [102]. CRC therefore distinguishes itself from many other common and serious cancers by being amenable to effective intervention if diagnosed in the early malignant or precursor stages. However, this is generally not achieved, despite the emphasis on patient education to recognize and act on symptoms, and the promotion of population-based screening programmes. The societal costs associated with healthcare interventions and lost productivity are significant. In the UK, no more than half of CRC patients are diagnosed at Duke's stage A or B ( $<15 \%$ at stage $\mathrm{A})$ [20]. With approximately 16,000 deaths per year, even a small 'shift to the left' in stage at diagnosis could represent meaningful individual and societal benefits.

There is no contradiction in suggesting that primary prevention approaches to reduce CRC incidence should be complemented by surveillance efforts that are targeted as accurately as possible on those most likely to benefit. Current screening programs are effective in reducing CRC mortality [21,22], but colonoscopy is an invasive intervention with defined harms, and consumes expert resources, which are in limited supply. Even small reductions in the inevitable false-positive and -negative rates associated with the first stage screening (age and fecal occult blood tests) would lead to better matching of colonoscopy to those at highest risk, and avoidance of unnecessary procedures in the lowest risk groups. Thus, incorporating $\mathrm{FH}$ information into surveillance protocols is likely to improve selection of individuals for screening colonoscopy. This is to the benefit of the entire population eligible for screening, and to society as a whole, which ultimately provides the resources that make surveillance programmes possible, although it may often be impossible to point towards the specific benefits for each individual.

\section{Capturing \& using FH information in CRC care}

Generally speaking, FH information seems to be under-utilized by clinicians involved in CRC care across all health settings. Multiple studies have documented deficiencies in the recording of cancer FH information in patients' records [23-28], even in situations that should raise a red flag, such as younger patients being treated for CRC [29]. It also appears that recording positive $\mathrm{FH}$ information in a patient's chart does not guarantee that it will be acted upon [30]. This situation is compounded by the tendency for patients to underreport CRC in their relatives. Reports of bowel cancer in a relative can generally be believed, but in some studies only a third of relatives actually affected by CRC were reported [19]. However, it seems that under-reporting is more likely for second-degree or more distant relatives (suggesting unawareness or confusion over diagnosis), so the most important preliminary risk assessment $\mathrm{FH}$ - parents and siblings - may be reasonably expected to be fairly accurate.

Promoting the more extensive use of $\mathrm{FH}$ information in CRC care also needs recognition that changing practice faces many barriers [20]. The simplest suggestion is to raise health professionals' awareness of the value of $\mathrm{FH}$, and to provide them with tools to assist them [17]. There is good evidence to suggest that using a FH tool (of any kind) seems to promote completeness and accuracy of information [31], and informatics infrastructures to support the use of electronic medical records may facilitate this process [32]. However, this does not guarantee its use as intended in clinical decision-making [33]. There is ample evidence that the most widely agreed-upon, effective health interventions are underused [34], and that passive approaches to promoting evidence-based practice do not automatically lead to their adoption [35].

Recognizing this, there are avenues of enquiry and action that may promote the appropriate integration of FH into CRC care. Firstly, while the evidence base on the association of $\mathrm{FH}$ and CRC is clear, how this might translate into benefits, harms and costs for any given population is not. The overall consequences of widely adopting $\mathrm{FH}$ in risk assessment are influenced 
by the underlying prevalence of CRC, and the effectiveness of existing policies on prevention, screening and treatment. Veenstra et al. developed a risk-benefit framework that emphasizes drawing together evidence on shifts in risk classification, clinical interventions, patient behavior, life expectancy and quality of life when a new 'test' (like FH) is added to existing protocols [36]. Such an analysis may be very revealing and help clarify the level of emphasis that FH warrants in comparison with other interventions to reduce CRC morbidity and mortality.

If analysis of risks, costs and benefits justifies efforts to use FH, then this should be reflected in the relevant professional guidance. Presently, CRC guidelines have variable recommendations on the use of FH [37]. While the challenges of integrating $\mathrm{FH}$ collection into routine practice [20] will not be overcome by simply disseminating a guideline, theory-informed approaches to changing practice are emerging [38].

Finally, we should recognize the role of patients and the public in promoting improvements in their own clinical care. Since 2004, the US Surgeon General has promoted an annual 'National Family History Day'. Families gathering for the Thanksgiving celebration are encouraged to talk about their health problems, supported by an online tool (My Family Health Portrait) [103]. Reaching out to the public as agents of change within a healthcare system aligns with the movement towards personalized medicine and patientdriven healthcare, and may be an entirely appropriate way to think about patients, families and shared responsibility for health [39].

\section{Financial \& competing interests disclosure}

The author has no relevant affliations or financial involvement with any organization or entity with a financial interest in or financial conflict with the subject matter or materials discussed in the manuscript. This includes employment, consultancies, honoraria, stock ownership or options, expert testimony, grants or patents received or pending, or royalties.

No writing assistance was utilized in the production of this manuscript.

\section{References}

1 Yoon PW, Scheuner MT, Peterson-Oehlke KL, Gwinn M, Faucett A, Khoury MJ. Can family history be used as a tool for public health and preventive medicine? Genet. Med. 4, 304-310 (2002).

2 Berg AO, Baird MA, Botkin JR et al. National Institutes of Health State-of-theScience conference statement: family history and improving health. Ann. Intern. Med. 151, 872-877 (2009).

3 de la Chapelle A. Genetic predisposition to colorectal cancer. Cancer 4(10), 769-780 (2004).

4 Strate L, Syngal S. Hereditary colorectal cancer syndromes. Cancer Causes Control 16, 201-213 (2005).

5 Pinol V, Castells A, Andreu M et al. Accuracy of revised Bethesda guidelines, microsatellite instability, and immunochemistry for the identification of patients with hereditary nonpolyposis colorectal cancer. JAMA 293, 1986-1993 (2005).

6 Butterworth AS, Higgins JP, Pharoah P. Relative and absolute risk of colorectal cancer for individuals with a family history: a metaanalysis. Eur. J. Cancer 42, 216-227 (2006).

7 Taylor DP, Burt RW, Williams MS, Haug PJ, Cannon-Albright LA. Population-based family history-specific risks for colorectal cancer: a constellation approach. Gastroenterology 138, 877-885 (2010).
8 Registry Committee, Japanese Research Society for Cancer of the Colon and Rectum. Clinical and pathological analyses of patients with a family history of colorectal cancer. Jpn J. Clin. Oncol. 23, 342-349 (1993).

9 Chan JA, Meyerhardt JA, Niedzwiecki D et al. Association of family history with cancer recurrence and survival among patients with stage III colon cancer. JAMA 299, 2515-2523 (2008).

10 Kirchhoff AC, Newcomb PA, Trentham-Dietz A, Nichols HB, Hampton JM. Family history and colorectal cancer survival in women. Fam. Cancer 7, 287-292 (2008).

11 Zell JA, Honda J, Ziogas A, Anton-Culver H. Survival after colorectal cancer diagnosis is associated with colorectal cancer family history. Cancer Epidemiol. Biomarkers Prev. 17, 3134-3140 (2008).

12 Birgisson H, Ghanipour A, Smedh K, Påhlman L, Glimelius B. The correlation between a family history of colorectal cancer and survival of patients with colorectal cancer. Fam. Cancer 8, 555-561 (2009).

13 Kune GA, Kune S, Watson LF. The effect of family history of cancer, religion, parity and migrant status on survival in colorectal cancer. The Melbourne Colorectal Cancer Study. Eur. J. Cancer 28A, 1484-1487 (1992).

14 Slattery ML, Kerber RA. The impact of family history of colon cancer on survival after diagnosis with colon cancer. Int. J. Epidemiol. 24, 888-896 (1995).

15 Bass AJ, Meyerhardt JA, Chan JA et al. Family history and survival after colorectal cancer diagnosis. Cancer 112, 1222-1229 (2008).

16 Hemminki K, Li X, Dong C. Second primary cancers after sporadic and familial colorectal cancer. Cancer Epidemiol. Biomarkers Prev. 10, 793-798 (2001).

17 Guttmacher AE, Collins FS, Carmona RH. The family history - more important than ever. N. Engl. J. Med. 351, 2333-2336 (2004).

18 Qureshi N, Wilson B, Santaguida P et al. Collection and Use of Cancer Family History in Primary Care. Agency for Healthcare Research and Quality, MD, USA (2007).

19 Wilson BJ, Qureshi N, Santaguida P et al. Systematic review: family history in risk assessment for common diseases. Ann. Intern. Med. 151, 878-885 (2009).

20 Rich EC, Burke W, Heaton CJ et al. Reconsidering the family history in primary care. J. Gen. Intern. Med. 19, 273-280 (2004).

21 Hewitson P, Glasziou P, Irwig L, Towler B, Watson E. Screening for colorectal cancer using the faecal occult blood test, hemoccult. Cochrane Database Syst. Rev. (2), CD001216 (2000).

22 Kerr J, Day P, Broadstock M, Weir R, Bidwell S. Systematic review of the effectiveness of population screening for colorectal cancer. NZ Med. J. 120, U2629 (2007). 
23 Sweet KM, Bradley TL, Westman JA. Identification and referral of families at high risk for cancer susceptibility. J. Clin. Oncol. 20, 528-537 (2002).

24 Grover S, Stoffel EM, Bussone L, Tschoegl E, Syngal S. Physician assessment of family cancer history and referral for genetic evaluation in colorectal cancer patients. Clin. Gastroenterol. Hepatol. 2, 813-819 (2004).

25 Schroy PC, Glick JT, Geller AC, Jackson A, Heeren T, Prout M. A novel educational strategy to enhance internal medicine residents' familial colorectal cancer knowledge and risk assessment skills. Am. J. Gastroenterol. 100, 677-684 (2005).

26 Murff HJ, Greevy RA, Syngal S. The comprehensiveness of family cancer history assessments in primary care. Comm. Genet. 10, 174-180 (2007).

27 Tranø G, Wasmuth HH, Sjursen W, Hofsli E, Vatten LJ. Awareness of heredity in colorectal cancer patients is insufficient among clinicians: a Norwegian populationbased study. Colorectal Dis. 11, 456-463 (2009).

28 Kelly PP. Colorectal cancer family history assessment: documentation, deficiencies, and future directions. Clin. J. Oncol. Nursing 15, e75-e82 (2011).

29 Foo W, Young JM, Solomon MJ, Wright CM. Family history? The forgotten question in high-risk colorectal cancer patients. Colorectal Dis. 11, 450-455 (2009).

30 Butterly LF, Goodrich M, Onega T et al. Improving the quality of colorectal cancer screening: assessment of familial risk. Dig. Dis. Sci. 55, 754-760 (2010).

31 Qureshi N, Carroll JC, Wilson B et al. The current state of cancer family history collection tools in primary care: a systematic review. Genet. Med. 11, 495-506 (2009).

32 Feero WG, Bigley MB, Brinner KM; Family Health History Multi-Stakeholder Workgroup of the American Health Information Community. New standards and enhanced utility for family health history information in the electronic health record: an update from the American Health Information Community's Family Health History Multi-Stakeholder Workgroup. J. Am. Med. Inform. Assoc. 15, 723-728 (2008).

33 Wilson BJ, Carroll JC, Allanson J et al. Family history tools in primary care: does one size fit all? Public Health Genomics 15, 181-188 (2012).

34 McGlynn EA, Asch SM, Adams J et al. The quality of health care delivered to adults in the United States. N. Engl. J. Med. 348, 2635-2645 (2003).

35 Grol R. Successes and failures in the implementation of evidence-based guidelines for clinical practice. Med. Care 39(8 Suppl. 2), II46-II54 (2001).
36 Veenstra DL, Roth JA, Garrison LP, Ramsay SD, Burke W. A formal healthcare framework for genomic tests: facilitating the appropriate translation for genomics into clinical practice. Genet. Med. 12, 686-693 (2010).

37 Hasanaj Q. Family history in the assessment of risk for common complex diseases: current state of evidence. University of Ottawa, Canada (2011) (MSc Thesis).

38 Cane J, O'Connor D, Michie S. Validation of the theoretical domains framework for use in behaviour change and implementation research. Implementation Science 7, 37 (2012).

39 Swan M. Emerging patient-driven health care models: an examination of health social networks, consumer personalized medicine and quantified self-tracking. Int. J. Environ. Res. Public Health 6, 492-525 (2009)

\section{- Websites}

101 Globocan. Cancer fact sheet (2008). http://globocan.iarc.fr/factsheets/cancers/ colorectal.asp

102 Cancer Research UK. Bowel cancer survival statistics.

www.cancerresearchuk.org/cancer-info/ cancerstats/types/bowel/survival/bowelcancer-survival-statistics\#one

103 US Department of Health \& Human Services. Surgeon General's Family Health History Initiative. www.hhs.gov/familyhistory 